\title{
Cartas de indígenas potiguaras de las Guerras Holandesas en el Brasil (1645-1646)
}

Letters by Potiguara natives from Dutch Wars in Brazil (1645-1646)

\section{Leonardo Cerno y Franz Obermeier}

\section{(2) OpenEdition}

Journals

\section{Edición electrónica}

URL: http://journals.openedition.org/corpusarchivos/368

DOI: 10.4000/corpusarchivos.368

ISSN: 1853-8037

\section{Editor}

Diego Escolar

\section{Referencia electrónica}

Leonardo Cerno y Franz Obermeier, «Cartas de indígenas potiguaras de las Guerras Holandesas en el Brasil (1645-1646) », Corpus [En línea], Vol 3, No 1 | 2013, Publicado el 15 junio 2013, consultado el 21 abril 2019. URL : http://journals.openedition.org/corpusarchivos/368 ; DOI : 10.4000/ corpusarchivos.368

Este documento fue generado automáticamente el 21 abril 2019.

Licencia Creative Commons: Atribución-NoComercial 2.5 Argentina (CC BY-NC 2.5 AR) 


\section{Cartas de indígenas potiguaras de las Guerras Holandesas en el Brasil (1645-1646)}

Letters by Potiguara natives from Dutch Wars in Brazil (1645-1646)

Leonardo Cerno y Franz Obermeier

\section{NOTA DEL EDITOR}

Fecha de recepción del original: 10-14-2013

Fecha de aceptación para publicación: 14-05-2013

\section{Historia de los indios potiguara en el norte de Brasil}

1 Los potiguaras fueron una tribu tupí conocida en el Brasil colonial, desaparecida en el siglo XVIII. En la época colonial temprana sus asentamientos se situaban principalmente en la región costera de Paraiba a Ceará. Más tarde, debido a su alianza con los franceses, un grupo llegó a la colonia francesa en Maranhão².

Después de la derrota de los franceses y su pérdida de Maranhão en 1615, los potiguara fueron maltratados por los portugueses. Cuando intentaron aliarse con los holandeses de la Compañia de las Indias Occidentales en Paraiba, fueron abandonados por estos, y la mayoría murió a manos de los portugueses en la masacre de 1625, en un lugar que después tomó un nombre alusivo, la Baia da Traição. La invasión holandesa, en última instancia, había llevado a la separación política entre los miembros del grupo: una parte quedó aliada a los holandeses, otra parte a los portugueses. Esta división política de los potiguaras se refleja en sus cartas. 


\section{Los potiguaras aliados a los portugueses}

3 Antônio Felipe Camarão fue el más importante líder indígena militar que luchó contra los holandeses en el norte de Brasil. Educado por los jesuitas, fue bautizado en 1612 y recibió su nombre de pila. Como recompensa por sus logros militares, recibió el hábito de la Órden de Cristo y fue nombrado caballero por el rey portugués Don Felipe, recibiendo además el título de Governador y Capitão-Mor dos Índios. Murió en 1648. Antonio Filipe Camarão se convirtió en el héroe nacional brasileño de la liberación de los holandeses.

Diogo Pinheiro Camarão [Diogo da Costa] fue uno de sus parientes, probablemente un sobrino, y también un líder militar, un Sargento-Mor. En esa función firmó algunas de las cartas a Potĩ. Probablemente también era hermano o pariente de Potĩ (potĩ = camarón, Cf. Sampaio, 1913, p. 405). Después de la muerte de Felipe, fue nombrado Capitão-Mor do Terço dos Indios. Sirvió a los portugueses en las dos batallas de Guararapes y en otros combates. Murió en 1677.

\section{Los potiguaras aliados a los holandeses}

El jefe indígena Potĩ nació en Acejutibiró, en la mencionada Baia da Traição, pero pudo escapar de la masacre que los portugueses perpetraron allí. Potĩ había estado en los Países Bajos con Antônio Paraupaba. De vuelta en Brasil luchó por los holandeses y fue capturado en la segunda batalla de Guararapes en 1649. Durante su encarcelamiento sufrió maltrato por parte de los portugueses. Paraupaba menciona su tortura y su muerte en el Forte do Cabo de Santo Agostinho, en su segunda Remonstrantie de 1656, con detalles dramáticos.

6 Antônio Paraupaba era también un potiguara como los otros. En 1625 viajó de Brasil a Holanda con su padre Gaspar Paraupaba y con Potĩ, donde recibieron instrucción en nombre de la Compañía de las Indias Occidentales. Al parecer volvieron a Brasil en 1631, donde actuaron como intérpretes para los holandeses, figura necesaria ya que estos tenían la intención de reconquistar los territorios del Paraíba y la región de Pernambuco.

7 Paraupaba viajó por segunda vez a los Países Bajos, con la delegación brasileña que acompañó al jefe holandés de la colonia, Johann Maurits van Nassau-Siegen, tras su dimisión. En 1644 está de regreso en Recife, donde luchó contra los portugueses. Cuando los holandeses y sus aliados fueron derrotados en Guararapes (1649), Paraupaba se retiró con su tribu a la Sierra de Ibiapaba (entre Maranhão y Ceará), y se fue a los Países Bajos por tercera vez, escribiendo su primer documento en agosto de 1654. Llamó a su texto Remonstrantie (del francés remontrance 'protesta, objección'). Escribió una segunda Remonstrantie, que se imprimió junto con la primera (Cf. Hulsman, 2006, pp. 50 y ss). Paraupaba murió en Holanda en 1656 o poco tiempo después.

\section{Características y comparación con los documentos rioplatenses}

8 Existen siete cartas de octubre de 1645 , seis de ellas tratando de persuadir a los potiguara aliados a los holandeses a abandonar a estos y a luchar por los portugueses. La carta restante es una respuesta de Potĩ rechazando la oferta (la versión en portugués en Souto 
Maior, 1913, pp. 403-414). La correspondencia entre los Potiguara se presenta como un tipo de documento excepcional para la época colonial en América del Sur. Se trata de las únicas cartas indigenas que tenemos del Brasil colonial, un género de texto más común, a partir del siglo XVIII, en la región rioplatense. En el Río de la Plata, no obstante, el número de cartas entre indígenas es mucho menor en comparación con las cartas administrativas dirigidas a las autoridades. En el Brasil no hubo el tipo de escrituralidad a fines administrativos que existió en las reducciones jesuíticas del Paraguay. Sabemos no obstante que tales documentos existieron ${ }^{2}$, mas no se conservaron o no fueron hallados hasta hoy. Este hecho da a pensar que en la situacion brasileña, en donde el indígena no fue incluido como parte de la administración de las aldeias (por lo demás menos estables que las reducciones paraguayas), la escrituralidad indígena no pudo alcanzar el desarrollo que tuvo en Argentina.

sartas brasileñas hasta hoy no fueron objeto de una investigación lingüístico-histórica de mayor alcance. Algunos aspectos, no obstante, pueden ser discutidos aquí. Con respecto a su finalidad, esta debe verse dentro de un conjunto de prácticas que abarcaron tanto la escrituralidad habitual como la propaganda (el corpus total incluye un manifesto de propaganda entre indígenas). Una cuestión central representa saber si la escritura de las cartas fue inducida por los holandeses, o si se debió a la específica voluntad de esos grupos de indígenas combatiendo en dos bandos distintos de guerra. Esta cuestión toca, por lo demás, a la mayoría de los documentos escritos por indígenas. No obstante, en ese punto de la investigación, sobre todo ante la falta de una edición completa de los textos en tupí y de sus características lingüísticas, no se puede avanzar más que en hipótesis. Todos estos indígenas tuvieron un papel de mediadores entre la cultura de sus aliados europeos y su propia cultura. En el caso de Potĩ y Paraupaba, de sus varias estadías en Holanda se puede deducir que recibieron allí una formación que les habilitó a trabajar como intérpretes y capitanes militares a la vez. Por su parte, los indígenas aliados a los portugueses formaron parte de una élite indígena que fue preparada y favorecida como tal y que tuvo en la jerarquía militar un rango mayor al de los jefes indígenas comunes, hecho que se observa en los honores excepcionales que recibió Antônio Felipe Camarão después de la victoria militar portuguesa y en su mitificación posterior como héroe nacional indígena del Brasil.

En esta selección presentamos dos cartas escritas por Diogo Pinheiro Camarão a su primo Potĩ. La primera carta que ofrecemos, la mejor reconstruida desde el punto linguístico, fue publicada recién en 1998 (Almeida Navarro, 1999, pp. 527-531). La segunda carta, publicada por Theodoro Sampaio (Sampaio, 1907, pp. 294 y ss), se presenta aquí con la grafía antigua del tupí ya que una reconstrucción a partir del original constituye una tarea compleja y todavía por hacerse. Los préstamos del portugués en el tupí se destacan con subrayado. La traducción al español es nuestra.

11 Hasta el momento es difícil pensar en una edición completa y crítica del corpus, ya que las transcripciones y traducciones existentes, dados sus errores, merecen una revisión a partir de los originales en tupí. Las cartas originales fueron escritas por los autores mismos, sin la ayuda de secretarios, como se induce a partir de la comparación de la escritura de estos documentos con otros, por ejemplo con una solicitud firmada en 1661 por Don Diogo Pinheiro Camarão y todavía conservada ${ }^{3}$. 


\section{Carta 1}

12 Ao Sñor Capitão Pedro Potĩ Îande Îara Pa'i Tupã t-ecobé-katu t'o-me'eng endébe. Iko xe papera (< papel) endé s-epiak' îanode, xe-rory-katu 'ã opabenhe瞖 pe marane'yma r-esé gûi-poradupa, xe

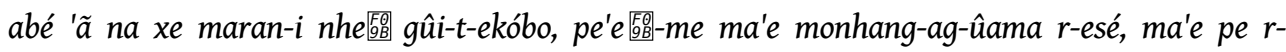
emimotara. Ma'e monhang-ag-ûama r-esé, a-î-mondó 'ã xe soldados ebapó nde r-apé ypy-pe, pe

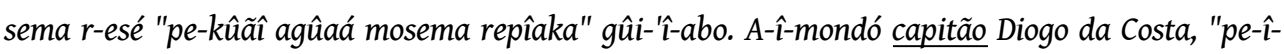
pysyk abá amõ koîpó kunhã amõ ta pe-î-mongetá." "-Pe r-enosema ikó oro-îur pe-îé i xupé. Pe-1mongetá ranhe媐. I mongetá roîré, ta pe-îmodó agûaá-monga kuapa" gûi-'î-abo.

Pa'i Tupã Îandé Îara r-emi-guab-amo, ikó xe nhe'enga a-î-mondó endébe, Sr. Pedro Poti. Marãnamo xe 'ã nde anama r-eté-katu? E-îor e-sema Anhanga r-atá nungara suí. E-î-kuab christão-

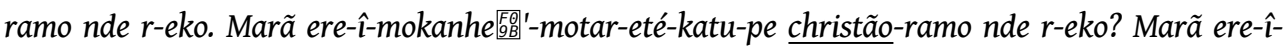
mokanhe䜿'-motar-eté-pe Pa'i Tupã r-a'yr-amo nde r-eko? Marã ere-îko-potar-eté-pe? T-ekó kuab-

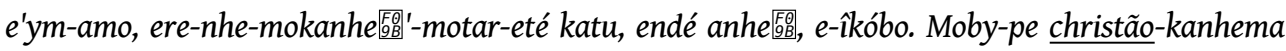
ere-s-epîa(k)? Karaiba na o-kanhe-ba'e ruã. Marã-namo christão-ramo s-ekó-reme, nd'i katú-î, Pa'i Tupã i-mokanhema? Ikó bé oro-îcó pe r-enosema motá, sñor Capitão-Mor Antônio Felipe Camarão

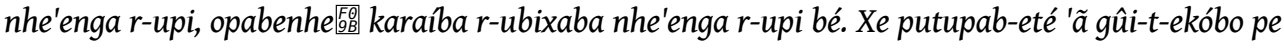
r-esé, oré suí pe nhengûasema r-epiaka. Na pe anama ruã-te-pe oré? Ma'e r-esé-pe oré amotare'ym

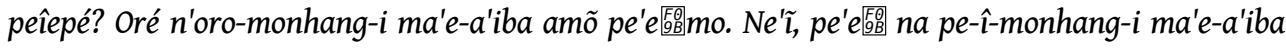
amõ orébe. Emokûê̂-pe Capitão-Mor papera só-û endébe. Emokûuế-pe Antônio Paraopeba supé amõ Capitão-Mor papera só-û.Pa'i Tupã temõ o-îké pe py'a-pe-mo, cristão gûé! A'e-mo pe-se颐'-me orér-

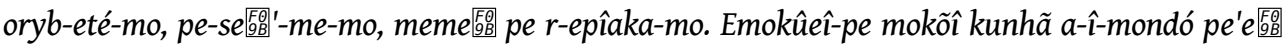
me, moranduba r-erasóbo, t'o-mombe'u ké xe r-ekó endébe. Aîpó nhõ moranduba só-û. Pe-îkobékatu pe-îkó-bo. Pa'i Tupã t'o-îkó pe iru䜿-namo. Hoje, 21 de outubro, 1645 anos. Nde r-ybyra, nde raûsup-ara, Sargento-Mor Dom Diogo Pinheiro Camarão

\section{Versión en español}

14 Al Señor Capitán Pedro Potĩ. Nuestro Señor te dé una buena vida. Antes de que veas esta carta, yo estoy muy feliz, preguntando por todas las cosas buenas de ustedes, yo también no estando mal, en efecto, para que ustedes hagan las cosas, las cosas que ustedes desean. Para hacer las cosas, envié a esos mis soldados allí, cerca de tus caminos, para la salida de ustedes, diciéndoles "vayan a evacuar los altibajos". Mandé al capitán Diego Acosta, [diciéndole] "tomen allá algunos hombres o algunas mujeres para conversar. Díganle a ellos 'vinimos para salvarlos'. Conversen con ellos primero. Después de conversar, que los envíen a ellos para que conozcan los altibajos pantanosos"

Como cosa sabida por nuestro Señor Dios, te envío estas mis palabras, señor Pedro Potĩ. ¿Por qué es que soy un genuino familiar tuyo? Ven, sal de aquello que es como el fuego del Diablo. ¿Sabías que eres cristiano? ¿Por qué quieres perder definitivamente tu vida como cristiano? ¿Por qué quieres perder tu naturaleza de hijo del Señor Dios? ¿Qué es lo que quieres realmente hacer? Sin conocer la situación, ciertamente estás queriendo perderte a tí mismo. ¿Cuántos cristianos perdidos ya viste? Virtuosos son los que no se pierden. ¿Por qué, siendo cristianos, no son buenos, perdiéndose del Señor Dios? Aquí estamos, queriendo la salida de ustedes, por las palabras del Capitán Mayor Antônio Felipe Camarão, y también por las palabras del jefe de todos los blancos. Estoy atónito por causa de ustedes, al verlos huir de nosotros. ¿No somos más, nosotros, la familia de 
ustedes? ¿Por qué no nos quieren? Nosotros no les hicimos nada malo. Ea, ustedes tampoco nos hicieron nada malo. Hacia allá va también una carta del Capitán Mayor para tí. Para allá van también algunas cartas del Capitán Mayor para Antonio Paraopeba. ¡Ojalá el Señor Dios entre en los corazones de ustedes, oh, cristianos! Seríamos muy felices si ustedes salieran, y así poder verlos siempre. Allá envié dos mujeres llevando noticias a ustedes, para que ellas te cuenten cómo estoy. Solo estas noticias van. Que estén bien. Que el Señor Dios esté acompañándolos. Hoy, 21 de octubre, año 1645. Tu primo y tu amigo, Sargento Mayor Don Diogo Pinheiro Camarão.

\section{Carta 2}

Pay-tupã aé che papera aymondó ndêbe. Mãe tecópe ereymõ acy? Mãe monhang byteripe? Mãepe ereymo acy? Eyor, ecema. Acoimõbé aicó che caneõramo ndê recê. Ndê ríquey rahé Capitão-Mor abamemã ndêribyra Saligento-Mor abé. Ecema, ico che papera repiaca rupibe. Marãpe ereycó apiaba ayba rauçupa ichébe? Na che rauçubype? Marãpe reyçog che ganado eipo abé? Eyahó chebe che péabo; ndê yocê echépemo. Carayba ndê angáu na imombeú icué ndêbe opotareté carayba morubichaba ndé cema coribetê niã opabinhé caraybetá paraybiguara; ndê nheengaguera nirime; ndê cema abaeyma, eci mo ou abá mo che nheenga cuaapa tacó ndê reú.; acema coipo ndê ycú cuapaba rupi. Omimotar niã morubichaba ndê cema recê moeyma cûetê ndetá. Eyor, ecema. Nache rauçu peyépe! Omanõ cõi ndê ribyra Lippe Tocaia. Yandê co omanõ. Meguipe aiponhóte ndê ribyra ndê riquey Capitão Diogo da Costa ne ndaecetê de Outubro 1645 annos.

\section{Versión en español}

17 Es del Padre Dios que yo te mando mi carta. ¿Qué salud estás pasando? ¿Que haces ahora? ¿Qué haces tú hermano? Ven, sale. ¿Desde hace cuánto estoy fatigado por causa tuya? Tu hermano también, el capitán mayor el viejo, tu hermano el sargento mayor también. Sale, luego de que veas esta mi carta. ¿Por qué razón estás enfadado conmigo que soy tu pariente? ¿No soy yo tu amigo? ¿Por qué maltratas mi ganado sin causa también? Retírate para mí, para mi destierro, sigue mi consejo. Los blancos muchas veces no te contaron cuánto deseaban los jefes blancos que salieras cuanto antes, junto con todos los moradores blancos de Parahyba. Si salieras sin gente, aproxímate, haz que venga un hombre a hablarme, avisando que es cierta tu venida. Entonces yo saldré a tu encuentro hasta el lugar donde te hallares. El jefe quiere ciertamente tu salida, sin hacer cuestión por los tuyos. Ven, sale. ¿No me estiman ustedes? Ha muerto tu hermano Felippe Tocaia. Nuestro amparo murió. Sólo estas cosas tiene para contarte tu hermano menor el Capitán Diogo Da Costa, a no muchos días de octubre de 1645.

Notas:

1. Ver los libros de los capuchinos franceses Claude d'Abbeville, Histoire de la mission [...], Paris, 1614 (nueva edición de Alfred Métraux y Jacques Lafaye, Graz 1964) y Yves d'Évreux, Suitte de l'histoire 1615 [impreso, mas no circuló, censurado], ed. crítica como Voyage au nord du Brésil, por Franz Obermeier, Kiel, 2012.

2. AntonioVieira, 1992, cit. en Neumann, 2005, p. 58. Los originales no se conocen.

3. Petição do Governador dos índios, Diogo Pinheiro Camarão, e de seu tenente, Antônio Pessoa, solicitando recursos para o sustento de suas famílias. Fecha: 23 de marzo de 1661, Petrópolis, Museu Imperial, versión digital: http://187.16.250.90:10358/dami/handle/acervo/643 


\section{BIBLIOGRAFÍA}

Almeida Navarro, Eduardo de (1999). Método moderno de tupí antigo. A língua do Brasil dos primeiros séculos. $2^{\circ}$ ed [ $1^{\circ}$ ed. de 1998]. Petrópolis: Vozes.

Cerno, Leonardo y Obermeier, Franz (En prensa). Nuevos aportes de la lingüística para la investigación de documentos jesuíticos de los siglos XVII y XVIII. Folia Histórica del Nordeste, 21. Resistencia: IIGHI-Conicet, 2013.

D’Abbeville, Claude (1963 [1614]). Histoire de la mission des pere s capucins en l'isle de Maragnon. Paris: Huby 1614. Ed. Jules Lafarge y Alfred Métraux. Graz: Adeva.

D’Évreux, Yves (2012 [1615]). Voyage au nord du Brésil. Éd. critique: Franz Obermeier. Kiel: Westensee-Verlag.

Hulsman, Lodewijk (2006). Brazilian Indians in the Dutch Republic. En: Itinerario, Leiden 29.1 (2005), traducción: “Índios do Brasil na república dos Países baixos, as representações de Antônio Paraupaba para os Estados Gerais em 1654 e 1656". Revista de História. Departamento de História da USP, 154 (2006): 37-69. En línea: revhistoria.usp.br/index.php? option=com_content\&view=article \&id =58\%3Arh-154\&catid=6\%3 Aedicoes \&Itemid=7\&lang=en Neumann, Eduardo (2005). Práticas letradas guarani, produção e usos da escrita indigena (séculos XVII e XVIII). Tesis Doctoral, Universidade Federal do Río de Janeiro. En línea: http:// www.dominiopublico.gov.br/pesquisa/DetalheObraForm.do?select_action=\&co_obra=107879 Obermeier, Franz (En prensa). Indigenous Letters in Colonial Brazil: a Tupí-correspondence during the Dutch Wars in 1645/1646. Ponencia presentada en Colonialism and Cultur of Writting - Language and Cultural Contact in Colonial Discourse Traditions. ZiF Bielefeld, Julio 2007, Ed. de las Actas a cargo de Rosa Yáñez Rosales.

Sampaio, Theodoro (1906). Cartas tupis dos Camarões. Revista do Instituto Archeologico e Geographico Pernambucano, Tomi XII, Nº 68 (1906), 201-305. En línea: http://biblio.etnolinguistica.org/ sampaio-1906-cartas

Souto Maior, Pedro (1913). Fastos pernambucanos. Revista do Instituto histórico e geográfico brasileiro. Rio de Janeiro. Tomo LXXV 1912, Parte I (1913), 259-504.

Vieira, Antonio (1992). Escritos sobre os índios. Ensaio introdutório de J.C. Sebe Bom Meihly. São Paulo: Loyola.

\section{Manuscritos originales}

Correspondencia entre Antônio Felipe Camarão, Diogo Pinheiro Camarão [Diogo da Costa], Poti y Paraupaba (1645-1646). Nationaal Archiev von Den Haag. "Brieven en Papieren" 1646. № 62. Compañia de las Índias Occidentales; version digital de los manuscritos (Brieven en Papieren, vol. Nr. 62, 52-59) http://www.gahetna.nl/collectie/archief/inventaris/index/eadid/1.05-01.01/ inventarisnr/62/level/file

Un documento pertinente a esas cartas se encuentra en Brieven en Papieren 1646. Nro 61 [61] Nr: 59, Brief (kopie) van Peter Pottij, te Paraiba, aan Pelipe Camarao en Diego da Costa. 1645 oktober 31. Una copia de ese texto existe como: [61] Nr.61, Brief (duplicaat) van Peter Pottij, te Paraiba, 
aan Pelipe Camarao en Diego da Costa. 1645 oktober 31. Disponible también a través de la página web htth:/www.gahetna.nl

\section{NOTAS}

1. Ver los libros de los capuchinos franceses Claude d'Abbeville, Histoire de la mission [...], Paris, 1614 (nueva edición de Alfred Métraux y Jacques Lafaye, Graz 1964) y Yves d'Évreux, Suitte de l'histoire 1615 [impreso, mas no circuló, censurado], ed. crítica como Voyage au nord du Brésil, por Franz Obermeier, Kiel, 2012.

2. AntonioVieira, 1992, cit. en Neumann, 2005, p. 58. Los originales no se conocen.

3. Petição do Governador dos índios, Diogo Pinheiro Camarão, e de seu tenente, Antônio Pessoa, solicitando recursos para o sustento de suas famílias. Fecha: 23 de marzo de 1661, Petrópolis, Museu Imperial, versión digital: http://187.16.250.90:10358/dami/handle/acervo/643

\section{RESÚMENES}

En esta contribución se presentan cartas intercambiadas entre grupos de indígenas potiguaras (tupíes) del nordeste de Brasil, unos aliados a los holandeses, otros a los portugueses. Estos documentos son excepcionales en el contexto del Brasil colonial. Escritas por indígenas que actuaron ellos mismos como líderes militares en el contexto de las Guerras Holandesas del Brasil (1645-1646), las cartas estaban destinadas a convencer a los potiguaras aliados a los holandeses a cambiar de bando y luchar a favor de los portugueses. Los indígenas habían sido alfabetizados por los europeos para quienes peleaban, como sabemos por diferentes fuentes. Estos documentos poseen un valor único para entender el impacto sociolingüístico de la escritura en la América indígena del siglo XVII.

The letters presented in this contribution were exchanged between two groups of Potiguara Indians in North eastern Brazil, one allied to the Dutch, the other to the Portuguese. They are exceptional for Colonial Brazil. Written by indigenous military leaders themselves in the context of the Dutch War (1645-1646), they should convince the Potiguara allied to the Dutch to change sides and fight with the Portuguese. The Indians had acquired their literacy skills with the Europeans they were fighting with, as we know from their biographical background. These unique documents are of great worth to understand the sociolinguistic impact of indigenous literacy in the 17 th century.

\section{ÍNDICE}

Keywords: Dutch Brasil Colony, Potiguara, Indigenous literacy, Indigenous leadership Palabras claves: Brasil holandés, Indios potiguara, Escrituralidad indígena, Liderazgo indígena 


\section{AUTORES}

\section{LEONARDO CERNO}

Universidad de Kiel, Alemania. Correos electrónicos: leonardo_cerno@yahoo.com.ar y obermeier@ub.uni-kiel.de

\section{FRANZ OBERMEIER}

Universidad de Kiel, Alemania. Correos electrónicos: leonardo_cerno@yahoo.com.ar y obermeier@ub.uni-kiel.de 